University of Nebraska - Lincoln

DigitalCommons@University of Nebraska - Lincoln

2012

\title{
Forty-year calibrated record of earth-reflected radiance from Landsat: A review
}

Brian L. Markham

Biospheric Sciences Laboratory, brian.I.markham@nasa.gov

Dennis L. Helder

South Dakota State University, dennis.helder@sdstate.edu

Follow this and additional works at: https://digitalcommons.unl.edu/nasapub

Part of the Physical Sciences and Mathematics Commons

Markham, Brian L. and Helder, Dennis L., "Forty-year calibrated record of earth-reflected radiance from Landsat: A review" (2012). NASA Publications. 70.

https://digitalcommons.unl.edu/nasapub/70

This Article is brought to you for free and open access by the National Aeronautics and Space Administration at DigitalCommons@University of Nebraska - Lincoln. It has been accepted for inclusion in NASA Publications by an authorized administrator of DigitalCommons@University of Nebraska - Lincoln. 
Review

\title{
Forty-year calibrated record of earth-reflected radiance from Landsat: A review
}

\author{
Brian L. Markham ${ }^{a}, *$, Dennis L. Helder ${ }^{b, 1}$ \\ a Biospheric Sciences Laboratory, Code 618, NASA/GSFC, Greenbelt, MD 20771, United States \\ b College of Engineering, South Dakota State University, Brookings, SD 57007, United States
}

\section{A R T I C L E I N F O}

\section{Article history:}

Received 27 February 2011

Received in revised form 16 June 2011

Accepted 23 June 2011

Available online $\mathrm{xxxx}$

\section{Keywords:}

Landsat

Radiometric Calibration

History

MSS

TM

$\mathrm{ETM}+$

\begin{abstract}
A B S T R A C T
Sensors on Landsat satellites have been collecting images of the Earth's surface for nearly 40 years. These images have been invaluable for characterizing and detecting changes in the land cover and land use of the world. Although initially conceived as primarily picture generating sensors, even the early sensors were radiometrically calibrated and spectrally characterized prior to launch and incorporated some capabilities to monitor their radiometric calibration once on orbit. Recently, as the focus of studies has shifted to monitoring Earth surface parameters over significant periods of time, serious attention has been focused toward bringing the data from all these sensors onto a common radiometric scale over this 40 -year period. This effort started with the most recent systems and then was extended back in time. Landsat-7 Enhanced Thematic Mapper $(\mathrm{ETM})+$, the best-characterized sensor of the series prior to launch and once on orbit, and the most stable system to date, was chosen to serve as the reference. The Landsat-7 project was the first of the series to build an image assessment system into its ground system, allowing systematic characterization of its sensors and data. Second, the Landsat-5 Thematic Mapper (TM) (still operating at the time of the Landsat-7 launch and continues to operate) calibration history was reconstructed based on its internal calibrator, vicarious calibrations, pseudo-invariant sites and a tie to Landsat-7 ETM + at the time of the commissioning of Landsat-7. This process was performed in two iterations: the earlier one relied primarily on the TM internal calibrator. When this was found to have some deficiencies, a revised calibration was based more on pseudo-invariant sites, though the internal calibrator was still used to establish the short-term variations in response due to contaminant build up on the cold focal plane. As time progressed, a capability to monitor the Landsat-5 TM was added to the image assessment system. The Landsat-4 TM, which operated from 1982 to 1992 , was the third system to which the radiometric scale was extended. The limited and broken use of the Landsat-4 TM made this analysis more difficult. Eight-day separated image pairs from Landsat-5 combined with analysis of pseudo invariant sites established this history. The fourth and most challenging effort was making the Landsat 1-5 Multi-Spectral Scanner (MSS) sensors' data internally radiometrically consistent. This effort was particularly complicated by the age of the MSS data, varying formats and processing levels in the archive, limited datasets, and limited documentation available. Ultimately, pseudo-invariant sites were identified in North America and used for this effort. Note that most of the Landsat MSS archived data had already been calibrated using the MSS internal calibrators, so this processing was embedded in the result. The final effort was developing an absolute scale for Landsat MSS similar to what was already established for the "TM" sensors. This was accomplished by using simultaneous data from Landsat-5 MSS and Landsat-5 TM, accounting for spectral differences between the sensors using EO-1 Hyperion data. The recalibrated history of the Landsat data and implications to users are discussed. The key result from this work is a consistently calibrated Landsat data archive that spans nearly 40 years with total uncertainties on the order of $10 \%$ or less for most sensors and bands.
\end{abstract}

Published by Elsevier Inc.

\section{Contents}

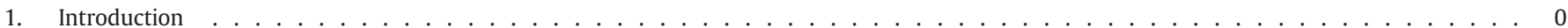

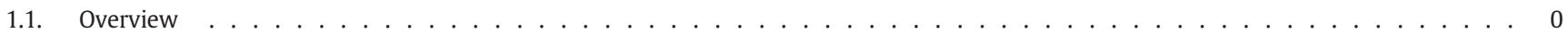

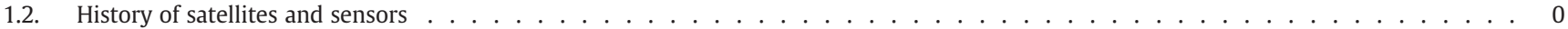

1.3. Basic sensor descriptions and radiometric calibration capabilities . . . . . . . . . . . . . . . . . . . 0

\footnotetext{
* Corresponding author. Tel.: +1 301614 6608; fax: +1 3016146695.

E-mail addresses: Brian.L.Markham@nasa.gov (B.L. Markham), Dennis.Helder@sdstate.edu (D.L. Helder).

Tel.: +1605688 4372; fax: +16056884969.
} 


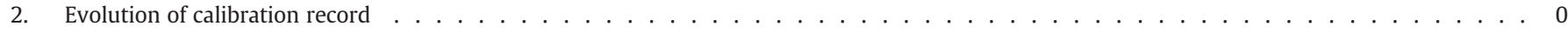

2.1. State as of $1999 \ldots \ldots \ldots \ldots$

2.2. Establishment of Landsat-7 ETM + as the standard: circa $2001 \ldots \ldots \ldots$

2.2.1. Landsat-7 mission improvements . . . . . . . . . . . . . . . . . . . . . . . . . . . . 0

2.2.2. Landsat-7 performance over 10 years (in press) . . . . . . . . . . . . . . . . . . . . . . . . . . 0

2.3. Reconstruction of Landsat-5 TM calibration and tie to Landsat-7 ETM+: 2001-2007 . . . . . . . . . . . . . . . . . . . . . . . . . . . 0

2.3.1. Phase $1: 1999-2003 \ldots \ldots \ldots \ldots \ldots \ldots$

2.3.2. Phase 2: circa $2007 \ldots \ldots \ldots \ldots$

2.4. Reconstruction of Landsat-4 TM calibration history and tie to Landsat-5 TM: circa 2008 . . . . . . . . . . . . . . . . . . . . 0

2.5. Reconstruction of Landsat-1 to Landsat-5 MSS calibration history: circa 2010 . . . . . . . . . . . . . . . . . . . . . . . . . . 0

2.6. Tie of Landsat MSS to Landsat TM radiometric calibration: circa 2011 . . . . . . . . . . . . . . . . . . . . . . . . . . . . 0

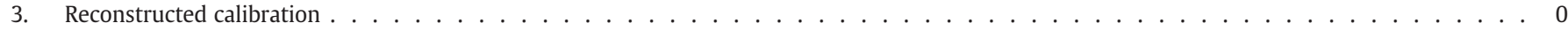

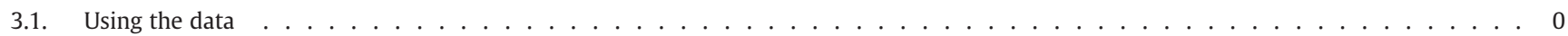

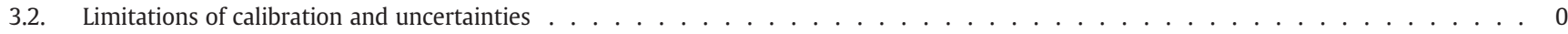

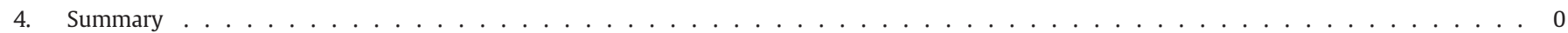

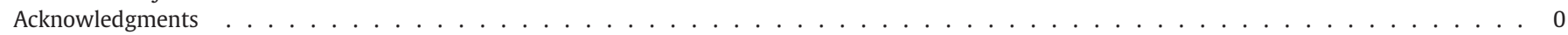

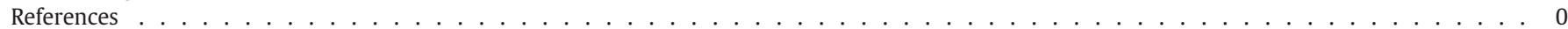

\section{Introduction}

\subsection{Overview}

With the launch of Landsat-1 in 1972, a new era in repetitive global coverage of the Earth's surface with moderate spatial resolution imagery commenced. Initially, much Landsat data analysis was by visual interpretation, or if by computer, involved training the computer to recognize certain targets based on within-scene statistics, i.e., classification. Although the Multi-Spectral Scanner (MSS) sensors on these early Landsat satellites were spectrally characterized and radiometrically calibrated prior to launch and did include capabilities for on-orbit radiometric calibration, there was little demand for consistent quantitative radiometric data and the emphasis in data processing was on limiting artifacts, a.k.a., destriping and producing visually consistent products. With the transition to the Thematic Mapper (TM) sensors in the early 1980s, the value of radiometrically calibrated data began to be recognized, i.e., retrieving Earth surface parameters by converting the sensor output to physical units (radiance) and then atmospherically correcting the data. These early analyses were severely hampered by the high cost of Landsat data products (up to $\$ 4000$, at times), resulting in part from the Landsat commercialization effort, particularly for time series analyses that required multiple Landsat scenes.

With the return of the Landsat system to US government control beginning in 1992 with the development Landsat-7 with its Enhanced Thematic Mapper Plus (ETM +) sensor and later with Landsat- 4 and -5 and their data archives, the data costs eventually were on the order of $\$ 600 /$ scene. This increased demand for these products. At the same time, the US government (jointly between the National Aeronautics and Space Administration (NASA) and the United States Geological Survey (USGS)) enhanced the Landsat ground processing system to include a staffed Image Assessment System (IAS) that provided for routine characterization of the geometry and radiometry of the data and calibration updates as necessary, significantly improving the quality and consistency of the data products. When the Landsat-5 system reverted to USGS control, efforts to bring these data into harmony with the recently launched and calibrated Landsat-7 ETM + peaked and the IAS was expanded to include Landsat-5 TM data. Since that point in time there has been a steady effort to bring all the Landsat systems into a consistent non-proprietary processing system that could be readily updated to provide products over the lifetime of Landsat. Dropping all user costs for the US Landsat data products, beginning in 2008 , has tremendously increased the demand for the data and has further driven this effort. The approach has been to systematically work backward from the present (Landsat-7 ETM + and Landsat-5 TM) to the past. Papers have been published about the details of much of this effort over the past 10 years or so, e. g., Teillet et al. (2001, 2004); Markham et al. (2004); Helder et al. (2008); Malla and Helder (2008); and a number of papers are in the process of being published on the last pieces of this effort, e.g., Helder et al. (in press-a, in press-b, in press-c); Markham et al. (in press). This paper summarizes analyses, results and implications for data users, and will rely heavily on referencing other work for the details of the process.

\subsection{History of satellites and sensors}

Table 1 provides a summary of the history of the Landsat series of satellites, including dates of operation and sensors (NASA, 2011). A power problem related to the Return Beam Vidicon (RBV) system stopped its use after the first two weeks on orbit for Landsat- 1 and although the RBV functioned on Landsat-2, it was used little. The RBV was modified for Landsat-3, converting it to a single band, higher spatial resolution (circa $30 \mathrm{~m}$ ) system. The RBV will not be discussed further in this paper. The Landsat-3 MSS had a thermal band, but it did not perform well. The TM's and ETM + also have a thermal band, whose calibration history is discussed in a companion paper (Schott et al., 2012-this issue).

Table 1

Landsat systems, operational dates and sensors.

\begin{tabular}{|c|c|c|c|c|}
\hline Satellite & Launch date & Decommissioning date & Sensors & \\
\hline Landsat-1 & July 23, 1972 & January 6, 1978 & MSS (4 band) & RBV (3 band) \\
\hline Landsat-2 & January 22, 1975 & February 5, 1982 & MSS (4 band) & RBV (3 band) \\
\hline Landsat-3 & March 5, 1978 & March 31, 1983 & MSS (5 band) & RBV (pan only) \\
\hline Landsat-4 & July 16, 1982 & June 2001 (last TM data transmitter failed 1993) & TM (7 band) & MSS (4 band) \\
\hline Landsat-5 & March 1, 1984 & Operating & TM (7 band) & MSS (4 band) \\
\hline Landsat-6 & October 5, 1993 & Failed to achieve orbit & ETM ( 8 band) & \\
\hline Landsat-7 & April 15, 1999 & Operating & $\mathrm{ETM}+(8$ band $)$ & \\
\hline
\end{tabular}




\subsection{Basic sensor descriptions and radiometric calibration capabilities}

Table 2 provides a summary of the MSS, TM and ETM + characteristics for the reflective portion of the solar spectrum. The MSS on Landsats 4 and 5 was modified to accommodate the lower altitude of Landsat- 4 versus the previous Landsats. Also, its solar calibrator was removed.

\section{Evolution of calibration record}

\subsection{State as of 1999}

During the time of the development and up to the launch of Landsat-7 in April 1999, the data products available in the United States from the currently operating and historical Landsat sensors were in a variety of formats from several different processing systems. Processing systems were operated by the United States Geological Survey (USGS) and by a commercial operator. Some data products for US government users were produced on a different system from those available to the general public. Most of the processing systems were proprietary and therefore publicly available information about the algorithms used in the systems was limited. The insight into how these processing systems operated was rather limited, even by the USGS as their operator; and the USGS's ability to update these systems with new constants or algorithms was complicated and not routinely performed. In general, data were processed with the same calibration constants and algorithms in place as when the satellites completed their missions and these constants and algorithms could be a function of both acquisition data and processing date. The state of the MSS radiometric processing systems is partially documented in Markham and Barker (1987), Helder (1993), and Markham and Barker (1986) including the radiometric algorithms being used and the radiometric scaling parameters for the final products.

\subsection{Establishment of Landsat-7 ETM + as the standard: circa 2001}

\subsubsection{Landsat-7 mission improvements}

A number of factors converged during the development of the Landsat-7 sensor and mission that led to a significant step forward in the quantitative use of the sensor data. Some of these were a result of improvements in technology in the 15 or so years between when the TM's and the ETM + were designed and fabricated. Others were a result of "lessons learned" from the earlier programs and the involvement of some core personnel on the instrument teams, science team and calibration/validation teams that had previous Landsat TM experience. Finally, some were a result of an evolution of the science data user community including the greater recognition of the value of continued calibration and characterization efforts for satellite sensors throughout their missions. These led to an improved sensor in terms of stability (both gain and offset), freedom from some image artifacts e.g., memory effect, scan correlated shift, (Helder and Ruggles, 2004), absolute calibration and characterization both pre- and post-launch, and the comprehensiveness of the acquired data.

Specific examples include:

A. Flight hardware

1. Ion-Assisted Deposition (IAD) significantly improved the stability of the spectral filters, both between ambient and vacuum conditions and over time in general.

2. A/D convertors were markedly improved between Landsat-5 TM and Landsat-7 ETM+, particularly in the area of step size uniformity.

3. Contamination control increased in visibility within NASA programs. The control of contamination on instrument and optics likely contributed to minimizing ETM + optic throughput degradation.

4. ETM + design changes as a result of the Landsat- 4 and -5 TM issues. Electronic changes effectively removed the memory effect and scan correlated shifts. The addition of an optical window in front of the cold focal plane eliminated the contaminant buildup on the cold focal plane and resulting fluctuations and degradations in cold focal plane band responsivity.

5. The addition of on-board calibration devices: (a) solar diffuser, that generally worked well, though it degraded, and (b) partial aperture solar calibrator that turned out to be not very useful.

B. Science Data Processing

1. Non-proprietary and publicly released data processing algorithms and software improved the understanding and ability to modify parameters and algorithms for radiometric and geometric processing.

2. A staffed image assessment system (IAS) was built into the data processing system. The IAS is an off line tool that is used to characterize sensor performance and data quality and update parameters regularly and algorithms as required.

Table 2

Landsat sensor characteristics.

\begin{tabular}{|c|c|c|c|c|}
\hline $\begin{array}{l}\text { Sensor } \\
\text { /satellite }\end{array}$ & $\begin{array}{l}\text { Nominal reflective } \\
\text { spectral bands }\end{array}$ & $\begin{array}{l}\text { Spatial resolution } \\
\text { (instantaneous field of view) }\end{array}$ & $\begin{array}{l}\text { Normal radiometric } \\
\text { quantization }\end{array}$ & $\begin{array}{l}\text { Radiometric calibration } \\
\text { capabilities }\end{array}$ \\
\hline MSS/Landsat 1-3 & $\begin{array}{l}500-600 \mathrm{~nm} \\
600-700 \mathrm{~nm} \\
700-800 \mathrm{~nm} \\
800-1100 \mathrm{~nm}\end{array}$ & 79 m (all bands) & $\begin{array}{l}\text { 6-bit (compressed) } \\
" \\
" \\
6 \text {-bit (linear) }\end{array}$ & $\begin{array}{l}\text { Shutter with calibration wedge neutral density filter } \\
\text { Solar calibrator Lansing and Cline (1975) }\end{array}$ \\
\hline MSS/Landsat 4-5 & $\begin{array}{l}500-600 \mathrm{~nm} \\
600-700 \mathrm{~nm} \\
700-800 \mathrm{~nm} \\
800-1100 \mathrm{~nm}\end{array}$ & $83 \mathrm{~m}$ (all bands) & $\begin{array}{l}\text { 6-bit (compressed) } \\
" \\
\text { 6-bit (linear) }\end{array}$ & $\begin{array}{l}\text { Shutter with calibration wedge neutral density filter; } \\
\text { Markham and Barker (1987) }\end{array}$ \\
\hline TM/Landsat 4-5 & $\begin{array}{c}450-520 \mathrm{~nm} \\
520-600 \mathrm{~nm} \\
630-690 \mathrm{~nm} \\
760-900 \mathrm{~nm} \\
1550-1750 \mathrm{~nm} \\
2080-2350 \mathrm{~nm}\end{array}$ & $30 \mathrm{~m}$ (all reflective bands) & 8-bit (all bands) & $\begin{array}{l}\text { Shutter with lamp transfer optics, } 3 \text { calibration } \\
\text { lamps with sequencer, radiance feedback control } \\
\text { Engel and Weinstein (1983) and Barker et al. (1985) }\end{array}$ \\
\hline ETM +/Landsat-7 & $\begin{array}{c}450-515 \mathrm{~nm} \\
525-600 \mathrm{~nm} \\
630-690 \mathrm{~nm} \\
760-900 \mathrm{~nm} \\
1550-1750 \mathrm{~nm} \\
2080-2350 \mathrm{~nm} \\
500-900 \mathrm{~nm}\end{array}$ & $30 \mathrm{~m}$ (All reflective bands except pan band) & 8-bit (all bands) & $\begin{array}{l}\text { Shutter with lamp transfer optics, } 2 \text { calibration lamps, } \\
\text { constant voltage control, Full Aperture Solar Calibrator, } \\
\text { Partial Aperture Solar Calibrator Markham et al. (1997) }\end{array}$ \\
\hline
\end{tabular}


C. Landsat Science Team and Land Cover Project Science Office

1. Though short lived, the Landsat Science Team formed the basis for a continuing joint government and university working group for calibration and validation.

2. A Landsat calibration working group, an outgrowth of a portion of the science team that has continued throughout the mission, brought together the government IAS staff with other university based teams primarily involved in the vicarious calibration of satellite instruments. Regular redundant vicarious measurements of Landsat calibration had been missing up until this point.

3. The continued NASA support for the Land cover Project Science Office (LPSO) allowed continued NASA participation in the post launch calibration and characterization mix, working alongside the IAS staff. LPSO funding covered the vicarious measurements beginning about 5 years after launch as well.

D. Closer working relationship with the National Institute for Standards and Technology (NIST)

Transfer radiometers directly calibrated at NIST were deployed to the $\mathrm{ETM}+$ vendor's facility during pre-launch testing to validate and adjust the radiometric calibration applied to the ETM + sensor prior to launch (Markham et al., 1998). These efforts were part of the larger Earth Observing System (EOS) calibration office efforts (Butler et al., 2003). This provided better characterization of the linearity of the $\mathrm{ETM}+$ response as well as reduced uncertainty in the absolute radiometric calibration.

E. Pseudo Invariant Calibration Sites (PICS)

The identification of pseudo-invariant sites by a number of investigators (e.g., Cosnefroy et al., 1996) provided an additional methodology for monitoring the stability of the Landsat-7 ETM+. The development of a long term acquisition plan (LTAP) for Landsat-7 significantly increased the number of times various sites were acquired around the world in the first year or so of Landsat-7 operations. After that point in time, the identified PICS were given a higher priority in the LTAP leading to more frequent acquisition.

\subsubsection{Landsat-7 performance over 10 years (in press)}

The radiometric stability of the Landsat-7 ETM + reflective bands has been continuously monitored over its $12+$ year lifetime using the on-board calibration devices with the IAS as well as vicarious calibration and PICS (Markham et al, 2004; Markham et al., in press). In general, the ETM + appears to be more stable than any device or technique used to monitor it to date. The on-board lamp 1, which is on during the vast majority of imaging, shows a change in ETM + response of nearly $30 \%$ in band 1 and decreasing changes in the longer wavelength bands (Table 3; Fig. 1). Lamp 2, which is used about $0.1 \%$ of the time, shows changes about one quarter of those observed for lamp 1, so clearly lamp or the lamp optical system change is a significant contributor to the overall changes. The diffuser data show overall changes similar in magnitude to the lamp 2 results, but spectrally different, with the largest decreases in the Near InfraRed (NIR) region, very little change in the Short Wave InfraRed (SWIR)- 1 band and a small increase in the SWIR-2 band. This is apparently the

\section{Table 3}

$\mathrm{ETM}+$ apparent changes in gain (percent) based on various on-board calibrators, vicarious calibrations and pseudo-invariant sites.

\begin{tabular}{llllll}
\hline Band & Lamp 1 & Lamp & Diffuser & \multicolumn{2}{l}{ PICS (linear fit) } \\
\cline { 5 - 6 } & & 2 & & Delta & Uncertainty \\
\hline 1 & -28.3 & -6.8 & -7.1 & -1.1 & 0.4 \\
2 & -24.8 & -4.6 & -7.0 & -0.3 & 0.2 \\
3 & -19.5 & -4.0 & -8.5 & -0.2 & 0.2 \\
4 & $-3.8^{\mathrm{a}}$ & $+0.8^{\mathrm{a}}$ & -11.8 & -1.3 & 0.4 \\
5 & -7.2 & $-0.8^{\mathrm{a}}$ & -2.4 & -2.2 & 0.3 \\
7 & $-1.9^{\mathrm{a}}$ & -0.9 & 1.9 & -2.7 & 0.5 \\
PAN & $-10.0^{\mathrm{a}}$ & $-2.5^{\mathrm{a}}$ & -9.0 & -0.4 & 0.4 \\
\hline
\end{tabular}

a Not monotonic.

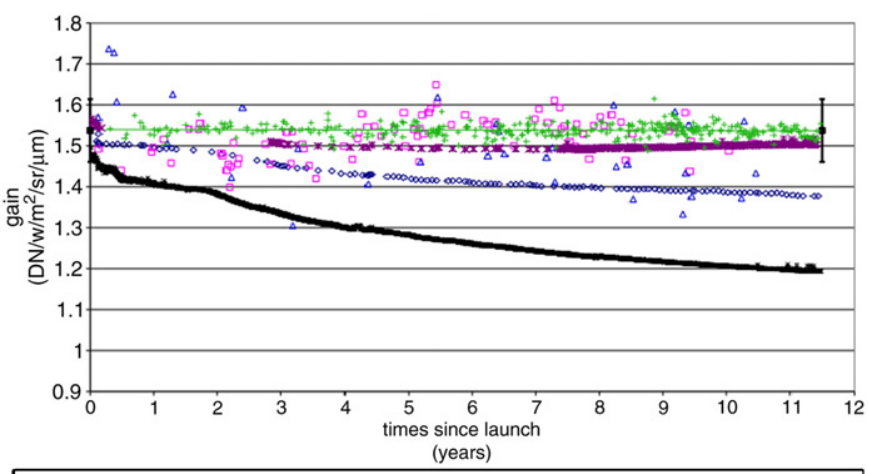

- On-board - Diffuser a Vicarius - U of Arizona $\triangle$ Vicarius - SDSU $\times$ On-board - Lamp $1 \times$ On-board - Lamp $2=$ Prelaunch +Pseudo-Invariant Sites

Fig. 1. Landsat-7 ETM + band 3 responses to on-board calibrators, vicarious calibrations and PIC sites over life of mission.

signature of the paint used on the solar diffuser. The vicarious measurements have the largest scatter of the various techniques and therefore are difficult to use to detect trends in response. The PICS results, though also with significant scatter and some systematic annual-like variation, have the advantage of a larger sample of data points. Currently, the PICS appear to be the most useful for detecting long-term trends in ETM+. The apparent trends, some of which are statistically significant, though the systematic variations make the statistics suspect, are generally small, i.e. less than $1 \%$ or so in the Visible \& Near Infrared (VNIR) bands and circa $2 \%$ in the SWIR bands total over 12 years. An independent study using PICS (Chander et al., 2010) showed changes in ETM + response of $2 \%$ or less over the first 10 years of the Landsat- 7 mission. These numbers likely give reasonable bounds to the amount of time-dependent error being introduced by using a fixed calibration over the current mission lifetime. Work is ongoing to try to remove some of the systematic variation in these datasets, e.g. due to atmospheric and Bidirectional Reflectance Distribution Function (BRDF) effects, to improve their utility for long-term instrument performance monitoring.

The requirement on absolute calibration of the ETM + was $\pm 5 \%$ (one sigma). Comparisons of the operational calibration and the initial calibration of the ETM + using the solar diffuser (based on the pre-launch measured reflectance of the diffuser and published solar irradiance curves) showed agreement to $4 \%$ or better overall and $2 \%$ or better in the VNIR (Markham et al, 2004). Estimates of the absolute calibration uncertainty using the vicarious measurements discussed above, i.e., the averages of the vicarious calibrations versus the operational calibration are presented in Table 4. Again, the differences are generally less than 3\%, with the exception of the South Dakota State University (SDSU) results in the two SWIR bands. Note, however, the vicarious measurements are almost all low relative to the operational calibration. Overall, results are consistent with the ETM + radiometric calibration uncertainty being $5 \%$ or less, perhaps as good

Table 4

Differences between operational ETM + calibration and vicarious calibrations: (vicarious-operational)/operational.

\begin{tabular}{llllll}
\hline Band & \multicolumn{2}{l}{ University of Arizona $(\mathrm{n} \sim 95)$} & & $\begin{array}{l}\text { South Dakota State University } \\
(\mathrm{n}=31)\end{array}$ \\
\cline { 2 - 3 } \cline { 5 - 6 } & $\begin{array}{l}\text { Mean } \\
\text { difference (\%) }\end{array}$ & $\begin{array}{l}\text { Standard } \\
\text { deviation }(\%)\end{array}$ & & $\begin{array}{l}\text { Mean } \\
\text { difference }(\%)\end{array}$ & $\begin{array}{l}\text { Standard } \\
\text { deviation }(\%)\end{array}$ \\
\hline 1 & $-3.3 \%$ & $2.4 \%$ & & $1.2 \%$ & $4.9 \%$ \\
2 & $-2.7 \%$ & $3.3 \%$ & & $-0.2 \%$ & $6.1 \%$ \\
3 & $0.6 \%$ & $3.1 \%$ & & $-0.6 \%$ & $7.0 \%$ \\
4 & $-0.6 \%$ & $2.8 \%$ & & $-1.1 \%$ & $5.2 \%$ \\
5 & $-2.9 \%$ & $2.4 \%$ & & $-7.2 \%$ & $5.6 \%$ \\
7 & $-2.2 \%$ & $2.9 \%$ & & $-7.6 \%$ & $6.9 \%$ \\
Pan & - & - & - & - \\
\hline
\end{tabular}


as 3\% and can serve as a good standard for the Landsat series of sensors.

\subsection{Reconstruction of Landsat-5 TM calibration and tie to Landsat-7 ETM+: 2001-2007}

There are a number of aspects to this calibration reconstruction that include: 1) artifact correction, primarily memory effect and scan correlated shift to improve the internal consistency of the data (Helder and Ruggles, 2004), 2) characterization of the effects of the build-up of ice on the cold focal plane window which affects the calibration of TM bands 5 and 7 (Helder and Micijevic, 2004) 3) development of the time history of the calibration based on on-board calibration sources, vicarious calibration and PICS (Teillet et al., 2004; Helder et al., 2008) and 4) anchoring the time history of the calibration to Landsat-7 ETM + (Teillet et al., 2001). A synopsis of the third and fourth aspects will be presented here.

\subsubsection{Phase 1: 1999-2003}

At the time of the Landsat-7 launch in 1999, a private company (EOSAT) had been operating Landsat- 5 for approximately 13 years. The emphasis of the radiometric processing during this period of time and before was on providing visually clean products, i.e., free from striping and banding and other artifacts. With the launch of Landsat-7 and commencement of operations under US government control in 1999, reduced data prices and increased data acquisitions, there was renewed scientific interest in the Landsat data for long term studies. This was further enhanced with the return of Landsat-5 to US government control in 2002. This development led to a new, largely retrospective look at the Landsat- 5 TM radiometric calibration.

Initial work emphasized the cross calibration of Landsat-5 TM with the recently launched Landsat-7 ETM+. A cross calibration opportunity with Landsat-5 TM had been designed into the commissioning phase of Landsat-7. For three days, the Landsat-7 ETM+ imaged areas within about 15 min of imaging by Landsat- 5 TM. The near simultaneous data sets, along with ground reflectance and atmospheric measurements made at several sites were used to perform the cross calibration (Teillet et al., 2001).

In nearly the same time frame, reconstruction of the calibration record was begun. At this time, the information available was from: (1) pre-launch measurements, (2) the lamp-based internal calibrator system and (3) a relatively sparse record of vicarious calibrations performed by the University of Arizona. Given that the lamp and vicarious calibrations both showed some trends, a fixed calibration, pre-launch or otherwise, was not appropriate, at least not for all bands. The internal calibration (IC) record, if limited to the best lamp, was smooth and discontinuity free. For this reason, a modified lamp record, using the best lamp and removing trends believed to be inherent in the calibration system itself was used as the basis for the calibration history (Teillet et al., 2004).

The IC record for Landsat- 5 when tied to an absolute scale via the June 1999 cross calibration with Landsat-7 ETM+, gave reasonably consistent results with the limited number of vicarious calibrations performed by the University of Arizona over the mission life (Fig. 2), so this result was selected to represent the TM calibration lifetime. Termed "Look Up Table 2003" (LUT03), it was used by the operational system to process Landsat-5 TM data from May 2, 2003 to April 20, 2007.

\subsubsection{Phase 2: circa 2007}

It was recognized when LUT03 was developed and released that it was a significant improvement over the previously used calibration technique, but that there was still some investigation needed. In particular, the vicarious calibration record was absent for a number of years (1988-1992), the vicarious calibration procedures had changed over the years and the selected LUT was not always a good fit to the

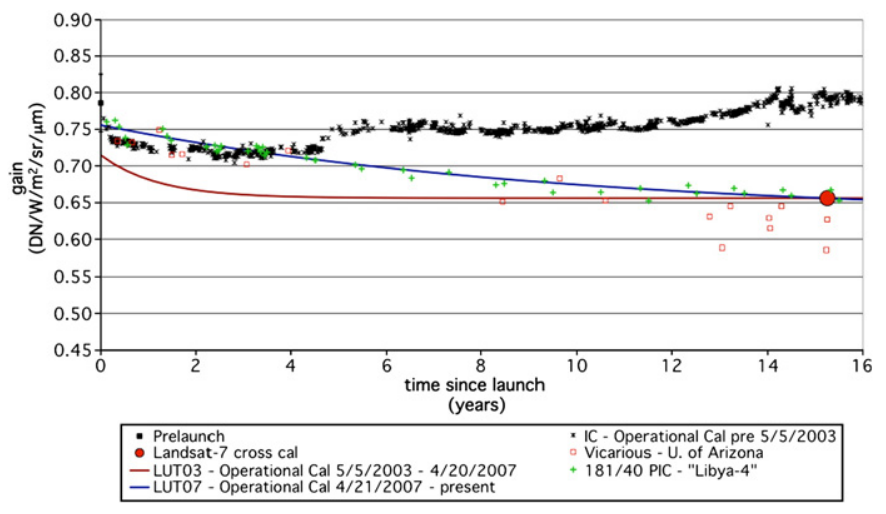

Fig. 2. Landsat-5 TM band 2 responses to on-board calibrators, vicarious calibrations and PICS and the history of operational calibrations applied to the data.

existing vicarious data. In an attempt to fill this gap in vicarious data and to provide a more continuous and consistent calibration record, PICS were investigated.

Cosnefroy et al. (1996) identified a candidate list of desert sites useful for monitoring the radiometric stability of satellite sensors. All these sites were in North Africa or on the Saudi Arabian peninsula. Unfortunately, coverage of any of these sites with Landsat-5 TM data in the USGS archives was extremely limited, i.e., insufficient to develop trends. Coverage of North America was quite robust, so a site in one of the driest areas of North America, the Sonoran desert in Mexico south of Yuma, Arizona was chosen. By treating some areas in the Sonoran desert as invariant sites, candidate responsivity trends were developed. Unfortunately, these data had considerable scatter and the correct trends were not obvious.

Searching the archive of Landsat-5 TM data revealed that path 181 row 40, essentially Libya 4 in Cosnefroy's terminology, was well represented in the European Landsat data archive. Through the cooperation of ESA, a good sampling of the Landsat- 5 coverage of this site was obtained. These data, adjusted for illumination variation due to solar zenith angle and earth-sun distance, showed clear trends, at least for TM bands 1-3 (Fig. 2, for example). Independent work by de Vries et al (2007) showed similar results, so these trends, anchored to the ETM + cross calibration point, formed the basis for LUT07. Effective April 21, 2007, LUT07 became operational in the USGS Landsat data processing system for Landsat-5 TM.

\subsection{Reconstruction of Landsat-4 TM calibration history and tie to Landsat-5 TM: circa 2008 (Helder et al., in press a)}

Once the proper calibration for Landsat-5 TM had been developed, the next logical step was to concentrate on Landsat-4 TM. Even though Landsat- 4 and 5 largely overlapped one another chronologically, calibration of Landsat- 4 TM was desirable to extend the coverage from 1984 back to 1982, and because Landsat- 4 data complemented Landsat- 5 data in that Landsat- 4 was tasked to cover international land areas, whereas Landsat- 5 focused more on the continental US region.

Initially, Landsat- $4 \mathrm{TM}$ was calibrated prior to launch through viewing of an integrating sphere that was traceable to the National Bureau of Standards (now NIST), and this calibration was transferred to the onboard calibration system (which was identical to Landsat-5 TM). Following launch, the onboard calibration system was used to calibrate all data collected by the instrument throughout its entire lifetime. An initial look at cross-calibration to Landsat- 5 was conducted by Metzler and Malila (1985) during an under-flight opportunity when Landsat-5 was first placed into orbit. Their results indicated that the two instrument gains were within $15 \%$ of each other. 


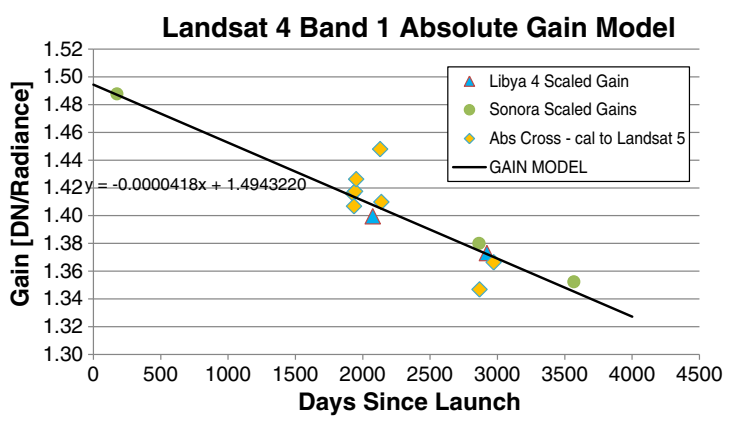

Fig. 3. Absolute calibration model for Landsat-4 Thematic Mapper, band 1 .

More recently, efforts were initiated to establish an accurate lifetime calibration record for Landsat-4 TM. These activities were begun by Mettler and Helder (2005) who used two PICS locationsthe Sonoran Desert near Yuma, Arizona, and a location near the Iraqi/Kuwait border to establish a cross-calibration with Landsat-5 through use of near simultaneous overpasses. The selection of these locations was driven primarily by the availability of data pairs within eight days of each other. Results from this work indicated that the reflective band calibration for Landsat- 4 TM was within $5 \%$ of Landsat- 5 TM in 1988 and 1991. An extension of this work by Malla and Helder (2008) using scene pairs that spanned dates from 1988 through 1993 produced similar results indicating the calibration for Landsat-4 TM had changed less than $5 \%$ over this extended time period.

These results showed good stability for the TM sensor on Landsat-4, but were still limited to point measurements. Trends recorded by the onboard calibration system were very similar to what had been observed from Landsat-5 TM, did not agree with the results just mentioned, and were deemed not useful for a temporal calibration of the instrument. So, to establish a continuous calibration record for the instrument, Helder used PICS locations in Sonora and Libya 4 (Helder et al., in press a). An example of these results is shown in Fig. 3. This plot shows the absolute calibration data (diamonds) that were obtained in 1988 and 1991, along with trending data from the two PICS shown as triangles. Even though the PICS trending data are sparse, there is a clear downward trend in the calibration of band 1 as shown by the black line. The remaining reflective bands for Landsat- 4 did not indicate any significant trend, and so the gain models for those bands are constant.

\subsection{Reconstruction of Landsat-1 to Landsat-5 MSS calibration history: circa 2010 (Helder et al., in press b)}

As mentioned previously, the first five Landsat satellites carried MSS sensors. These sensors acquired imagery of the Earth's surface from 1972 through 1992. As such, they add not only another decade of Landsat acquisitions, but also expand global coverage of the Landsat archive for 1982-1992.

Calibration of MSS data was historically performed through use of an onboard calibration lamp system (Markham and Barker, 1987). Like TM, the MSS was a whiskbroom scanner and, at the end of every second scan, the detectors were able to view the calibration lamp through a neutral density filter. Six different intensity levels from the lamp were recorded and regressed against coefficients derived during prelaunch calibration efforts to obtain gain and bias coefficients. Because the detectors in bands 1 through 3, which covered the visible and near infrared regions from 0.5 to $0.8 \mu \mathrm{m}$, were photomultiplier tubes, it was necessary to calculate multiple gain and bias coefficients during an image collect and combine them through use of a smoothing filter to minimize striping due to detector responsivity changes. An additional scene-based de-striping algorithm was implemented with Landsat-4 and 5 to equalize detector means and standard deviations.

MSS data were stored in the USGS Earth Resources Observation System (EROS) archive in a variety of formats commonly known as MSS-X, MSS-P, and MSS-A (Helder, 1993). The MSS-X data format was used for Landsats $1-3$. These data are stored in a radiometrically corrected format using the regression approach with onboard calibration lamps described previously. MSS-P data were archived for a short period of time from 1979 through 1981. This data format stored the imagery corrected both radiometrically and geometrically. Lastly, the MSS-A format, which was used for all of Landsat- 4 and 5 data, was only radiometrically corrected.

Since the historical calibration of MSS data was based on use of the onboard calibration lamp system with prelaunch gains and biases,
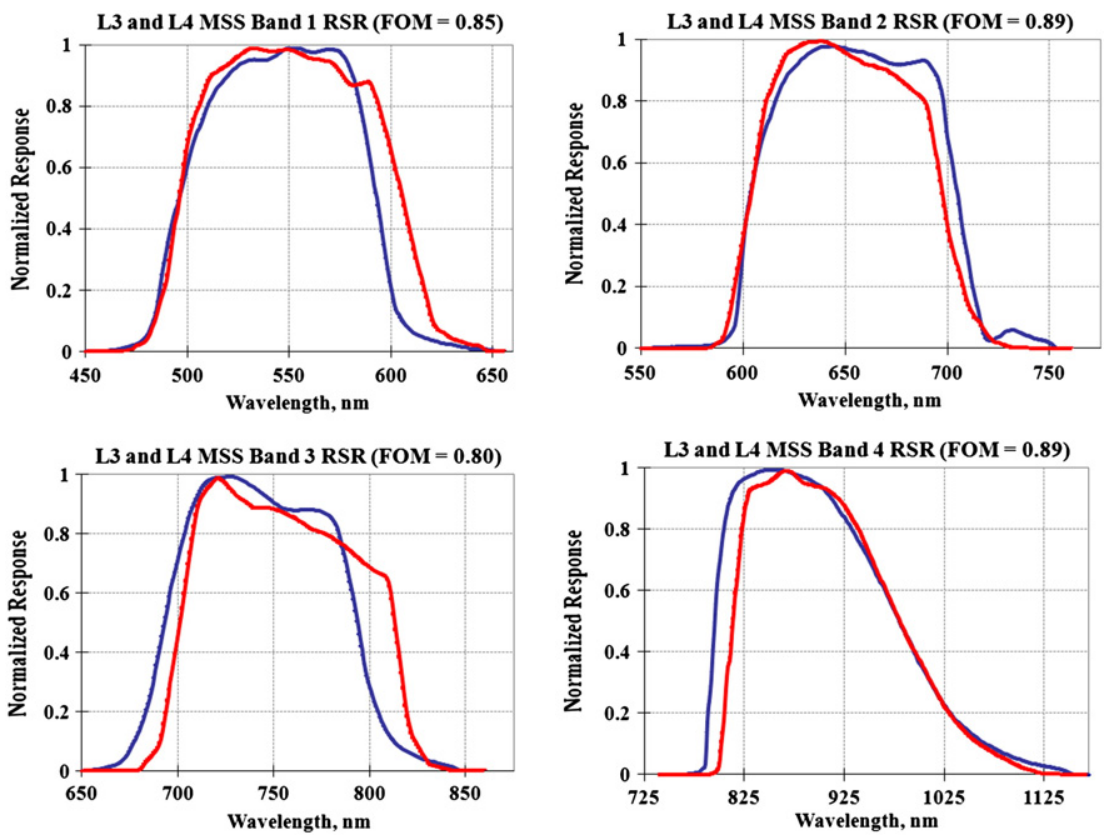

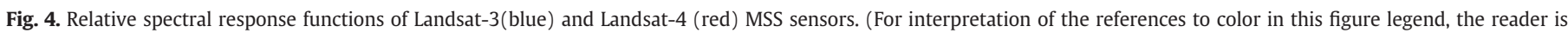
referred to the web version of this article.) 
with no updates during the lifetime of the instruments, significant differences in the calibration from one MSS sensor to another were known to exist. It was decided that cross-calibration of these sensors could best be established through the use of PICS as was done for Landsat- 4 and -5 TM (Helder et al., in press b). The most difficult part of this activity was the identification of appropriate PICS data sets. Since most of the MSS data available in the USGS EROS archive were of North America, the Sonora site was used extensively. Because of the potential for absolute calibration of the MSS sensor on Landsat5 , all of the other MSS sensors were cross-calibrated to Landsat-5 MSS in a stepwise fashion. That is, Landsat-1 was cross-calibrated to Landsat-2, Landsat-2 was cross-calibrated to Landsat-3, and so forth through to the cross-calibration of Landsat- 4 with Landsat-5.

A second difficulty with the cross-calibration of the MSS sensor series was the significant differences that existed in the spectral bandpasses of the sensors. This is illustrated in Fig. 4 which compares the average relative spectral response functions for Landsat-3 MSS to Landsat- 4 MSS. It was estimated that $1 \%$ error was possible simply due to spectral response differences. Lastly, since coincident collects were not available for most of the image pairs, the cross-calibration had to rely on near-coincident imaging events that occurred up to several days apart. This drawback allowed changes in the atmosphere to also affect the cross-calibration. Estimates of uncertainty are on the order of $4 \%$ for bands $1-3$ and up to $12 \%$ for band 4 due to the presence of a large water absorption feature in this particular band.

Despite these difficulties, good cross-calibration results were achieved across all MSS sensors. An example is shown in Fig. 5 for Landsat-2 MSS and Landsat-3 MSS. In this figure the cross-calibration across all four spectral bands is shown using three different scene pairs from 1979 through 1981. In each case, the imagery for each scene pair was obtained nine days apart. The data were very highly correlated and spanned a good portion of the dynamic range of both instruments. Unfortunately, a bias difference was discovered in three spectral bands for Landsat 1-3 MSS. This can be seen for two of the three cases in Fig. 5 for bands 2 and 3. In all other band/sensor combinations a simple

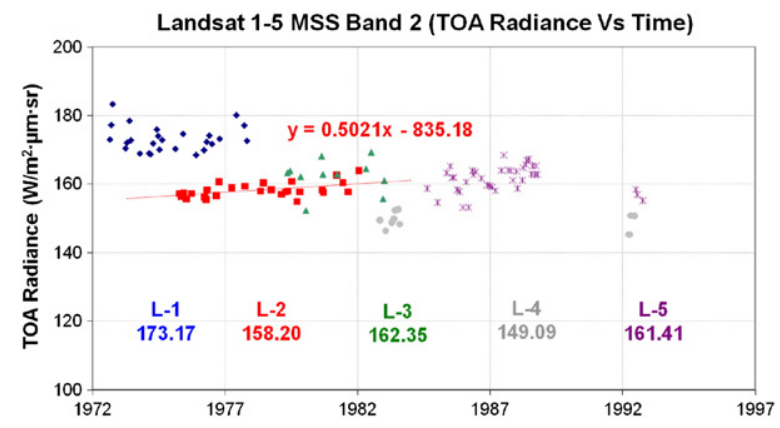

Fig. 6. Time series plot of TOA Radiance from Sonoran Desert site measured by band 2 of Landsats 1-5 MSS sensors before applying cross-calibration gains, biases and time dependent factor.

gain factor was all that was necessary to place the instruments on a common radiometric scale.

As an example of the differences that existed between MSS sensors, Fig. 6 shows the band 1 TOA radiance response of each sensor to the Sonora PICS after normalization for solar zenith angle and earth-sun distance. If the sensors were properly calibrated, each one would indicate the same radiance level for this invariant site. However, the figure clearly shows that the average radiance level recorded by Landsat- 1 MSS was greater than 154 radiance units, while the lowest level recorded was by Landsat-4 MSS at approximately 134 radiance units, a difference on the order of $15 \%$. In addition, this figure also shows that the response of Landsdat-2 and 3 MSS changed as a function of time as indicated by the dotted regression lines. Thus, a time dependent factor needed to be introduced to the calibration equation for these two bands (as well as for band 2 in Landsat-2 MSS).

After calibration has been applied to the data obtained from the Sonora PICS, the consistency of the sensors is substantially improved as shown in Fig. 7. Now each sensor's average response to the site is
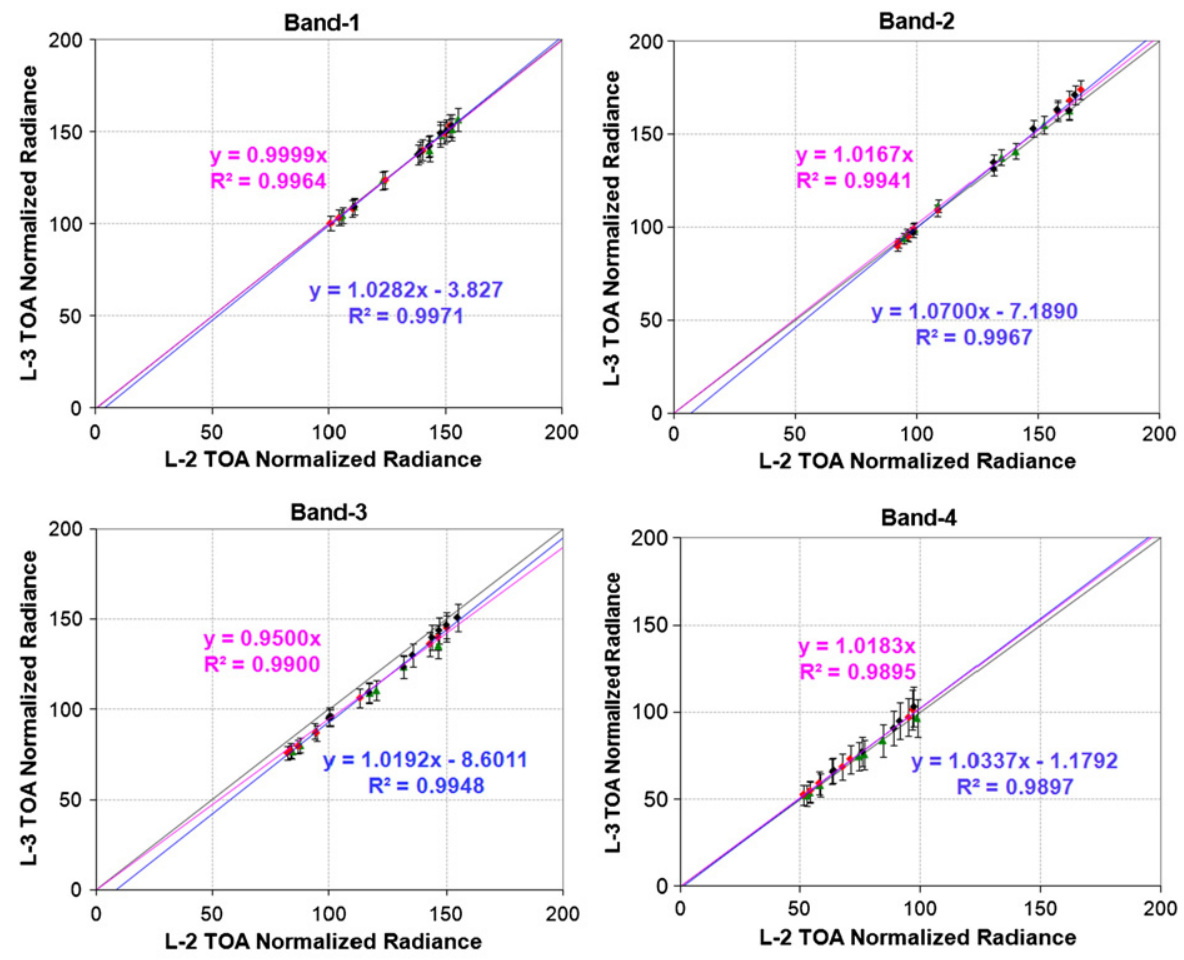

Fig. 5. Landsat-2 to Landsat-3 cross-calibration for band 1 through band 4 . 


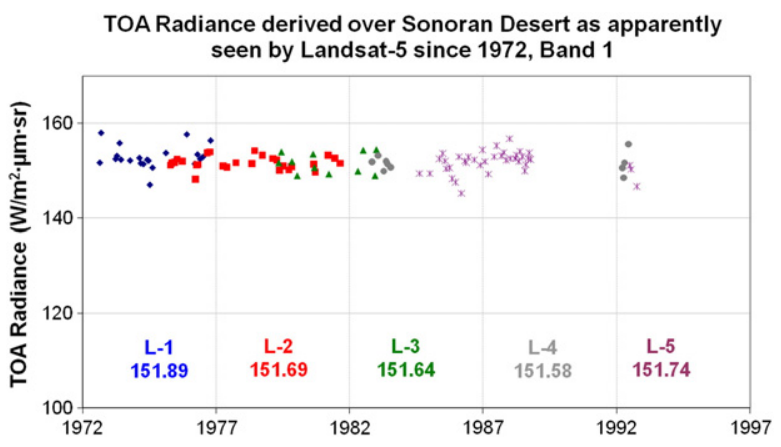

Fig. 7. Time series plots of TOA Radiance from the Sonoran Desert site as measured by band 1 of Landsats 1-5 MSS sensors after applying cross-calibration gains, biases and time dependent factor.

within $151.7 \pm 0.05$. Results for the other bands were similar with the exception of band 4 , which still exhibits an uncertainty on the order of $5 \%$ due to atmospheric absorption features.

\subsection{Tie of Landsat MSS to Landsat TM radiometric calibration: circa 2011} (Helder et al., in press $c$ )

Absolute calibration of the MSS sensors was accomplished by taking advantage of the fact that Landsat-5 carried both an MSS and a TM sensor (Helder et al., in press c). This provided many opportunities for coincident collection of imagery. Since Landsat-5 TM was well calibrated, it was used as a transfer radiometer for the calibration of Landsat-5 MSS. From there it was a simple matter to adjust the first four MSS sensors appropriately based on the results from the previous section.

It should be emphasized that the TM and MSS sensors have significantly different spectral responses as clearly shown in Fig. 8. Note especially that band 4 is much broader with the MSS sensor, and band 3 MSS really has no counterpart with respect to TM. Thus, the effort to place MSS on an absolute scale critically depends on an accurate knowledge of the RSRs of the two sensors, as well as the spectral
Table 5

Absolute gain ratios for Landsat-5 MSS to TM.

\begin{tabular}{lllll}
\hline MSS band:TM band & $1: 2$ & $2: 3$ & $3: 4$ & $4: 4$ \\
\hline ROI 1 & 0.823 & 0.914 & 0.949 & 0.951 \\
ROI 2 & 0.830 & 0.918 & 0.950 & 0.961 \\
ROI 3 & 0.826 & 0.909 & 0.945 & 0.951 \\
Average gain ratio & 0.824 & 0.914 & 0.948 & 0.955 \\
Percent uncertainty & $1.66 \%$ & $1.24 \%$ & $1.17 \%$ & $2.94 \%$ \\
\hline
\end{tabular}

signature of the test scene (target plus atmosphere). Secondly, it must be emphasized that MSS and TM cannot be expected to give the same radiometric response for targets that are not spectrally flat. To take into account the spectral differences between the two sensors, spectral band adjustment factors were calculated for each MSS band. These factors are basically the ratio of the radiometric response of the two sensors as shaped by their respected spectral filters in conjunction with the spectral signature of the target.

Once again the Sonora Desert PICS location was used for the absolute calibration of MSS. This was due to the well-known stability of the site, invariance to slight amounts of misregistration, and also due to the availability of coincident data pairs. For this analysis, 25 scene pairs were utilized spanning a large portion of the lifetime of Landsat5 MSS. Several locations were used to span a large dynamic range of the sensors. Lastly, three Hyperion scenes were available for the Sonora site and these served to guide the selection of the ROIs as well.

Table 5 shows the gain ratios obtained for Landsat- 5 MSS to TM. For all bands, the MSS response is slightly less than the TM response, ranging from $9 \%$ to $18 \%$. Good repeatability was obtained with all estimates within $3 \%$ of each other.

\section{Reconstructed calibration}

\subsection{Using the data}

As a result of the efforts described in this paper, all of the Landsat sensors have been placed on a consistent absolute radiometric scale.
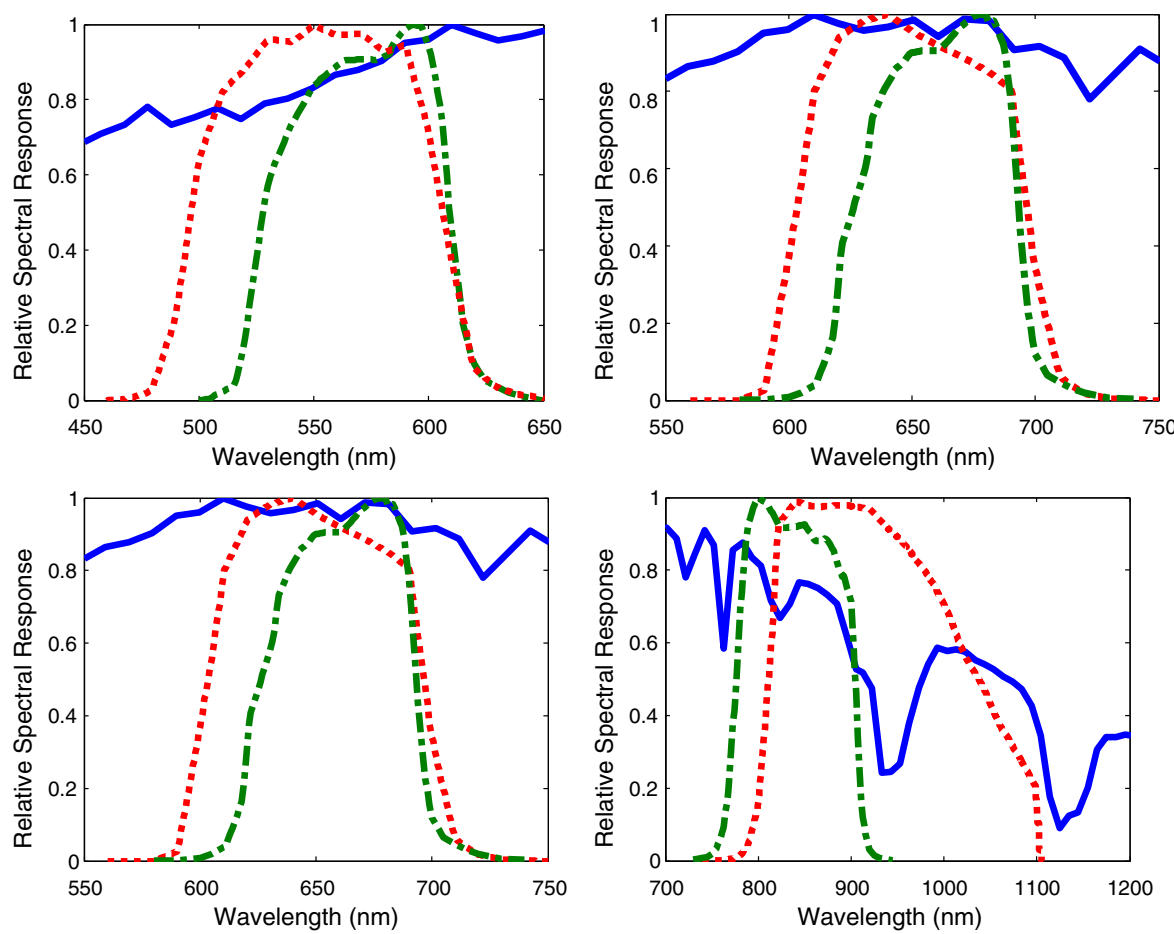

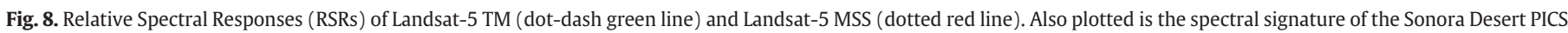
as obtained by Hyperion (solid blue line). (For interpretation of the references to color in this figure legend, the reader is referred to the web version of this article.) 
Table 6

Radiometric gain and bias values for Landsat 1-5 MSS archived data. Note: Data obtained from USGS/EROS after June 2011 have these factors applied.

\begin{tabular}{|c|c|c|c|c|c|c|}
\hline \multicolumn{3}{|c|}{ Landsat-1 MSS } & \multicolumn{2}{|l|}{ Landsat-2 MSS } & \multicolumn{2}{|l|}{ Landsat-3 MSS } \\
\hline & $\begin{array}{l}\text { Gain } \\
\mathrm{DN} /\left(\mathrm{W} / \mathrm{m}^{2} \cdot \mathrm{sr} \cdot \mu \mathrm{m}\right)\end{array}$ & $\begin{array}{l}\text { Bias } \\
(\mathrm{DN})\end{array}$ & $\begin{array}{l}\text { Gain } \\
\mathrm{DN} /\left(\mathrm{W} / \mathrm{m}^{2} \cdot \mathrm{sr} \cdot \mu \mathrm{m}\right)\end{array}$ & $\begin{array}{l}\text { Bias } \\
(\mathrm{DN})\end{array}$ & $\begin{array}{l}\text { Gain } \\
\mathrm{DN} /\left(\mathrm{W} / \mathrm{m}^{2} \cdot \mathrm{sr} \cdot \mu \mathrm{m}\right)\end{array}$ & $\begin{array}{l}\text { Bias } \\
(\mathrm{DN})\end{array}$ \\
\hline Band 1 & 0.6263 & 0 & ${ }^{\mathrm{a}} 0.5544$ & -3.98 & ${ }^{\mathrm{a}} 0.5712$ & -1.99 \\
\hline Band 2 & 0.7754 & -7.07 & ${ }^{\mathrm{a}} 0.7605$ & -0.54 & 0.7859 & -2.16 \\
\hline Band 3 & 0.7454 & 6.30 & 0.8681 & 2.12 & 0.9508 & -2.80 \\
\hline Band 4 & 0.7986 & 0 & 1.0358 & -3.67 & 0.9663 & -0.92 \\
\hline \multicolumn{4}{|c|}{ Landsat-4 MSS } & & \multicolumn{2}{|c|}{ Landsat-5 MSS } \\
\hline & \multicolumn{2}{|c|}{$\begin{array}{l}\text { Gain } \\
\mathrm{DN} /\left(\mathrm{W} / \mathrm{m}^{2} \cdot \mathrm{sr} \cdot \mu \mathrm{m}\right)\end{array}$} & $\begin{array}{l}\text { Bias } \\
(\mathrm{DN})\end{array}$ & & $\begin{array}{l}\text { Gain } \\
\mathrm{DN} /\left(\mathrm{W} / \mathrm{m}^{2} \cdot \mathrm{sr} \cdot \mu \mathrm{m}\right)\end{array}$ & $\begin{array}{l}\text { Bias } \\
(\mathrm{DN})\end{array}$ \\
\hline Band 1 & \multicolumn{2}{|c|}{0.5759} & -2.17 & \multicolumn{2}{|c|}{0.5765} & 1.44 \\
\hline Band 2 & \multicolumn{2}{|c|}{0.8031} & -3.17 & \multicolumn{2}{|c|}{0.7887} & -2.16 \\
\hline Band 3 & \multicolumn{2}{|c|}{0.9282} & -4.63 & \multicolumn{2}{|c|}{0.9352} & -4.44 \\
\hline Band 4 & \multicolumn{2}{|c|}{1.1472} & -4.54 & \multicolumn{2}{|c|}{1.1080} & -3.17 \\
\hline
\end{tabular}

a Time dependent factor applies.

Tables 6 through 10 provide the radiometric gain coefficients for all reflective bands of the archived data for all Landsat sensors (excluding RBV) to date. Table 6 lists the gain coefficients for Landsats 1-5 MSS. In addition, for three bands (Landsat-2 MSS bands 1 and 2, and Landsat-3 MSS, band 1) a time dependent factor (TDF) must be utilized as given in Table 7. For these bands, the TDF must be calculated as shown in the table as a function of time where $\mathrm{T}$ and $\mathrm{T}_{\text {Launch }}$ are in units of decimal years. The gain coefficients for those respective bands are divided by the TDF. Landsat- 4 radiometric gains are given in Table 8. For this instrument, all gains are constant except for band 1 . For band 1, radiometric gain is determined by multiplying the slope term $(-0.0000418)$ by the number of days since launch and adding the intercept term. Spectral radiance can then be calculated using the equation above. Sensor bias, B, is determined from onboard calibration shutter information at the end of each scan. Landsat-5 TM has an exponential model for all bands according to:

$G_{n e w}(t)=\alpha_{0} e^{-\alpha_{1}\left(t-t_{0}\right)}+\alpha_{2}$

where Gnew $(t)$ is the time dependent radiometric gain, time, $t$, is in years and $t_{0}=1984.2082$ (Helder et al., 2008). The gain model coefficients for Landsat-5 TM are listed in Table 9. Finally, Landsat-7 radiometric gains, Table 10, have not changed and can be used at any time.

Fortunately for the Landsat data user, beginning in June 2011, all of the above radiometric calibrations have been applied to the Landsat data ordered from USGS EROS. Since Landsat data products are now

Table 7

Time dependent factors for Landsat-2 and 3 MSS.

\begin{tabular}{lc}
\hline & Time dependent factor \\
\hline $\begin{array}{l}\text { Landsat-2 MSS } \\
\text { Band 1 }\end{array}$ & $\frac{147.72}{\left(0.56709 *\left(T-T_{\text {Launch }}\right)+144.85\right)}$ \\
Band 2 & $\frac{170.85}{\left(0.53916 *\left(T-T_{\text {Taunch }}\right)+168.11\right)}$ \\
Landsat-3 MSS & $\frac{151.55}{\left(1.5251 *\left(T-T_{\text {Launch }}\right)+144.10\right)}$ \\
Band 1
\end{tabular}

Table 8

Calibration gain model coefficients for Landsat-4 TM.

\begin{tabular}{llllllc}
\hline Model coefficient & Band 1 & Band 2 & Band 3 & Band4 & Band 5 & Band 7 \\
\hline Slope (gain/day) & -0.0000418 & 0 & 0 & 0 & 0 & 0 \\
Intercept (gain) & 1.494 & 0.719 & 0.954 & 1.073 & 7.708 & 14.65 \\
\hline
\end{tabular}

available from USGS EROS free of charge, users are encouraged to reorder their data sets to obtain the most recent, and accurate, calibration.

Data currently ordered from USGS EROS have had radiometric calibration applied to the standard terrain corrected product (L1T). The $Q_{c a l}$ values associated with the pixels have been rescaled to a normalized dynamic range with a maximum radiance value of $\mathrm{L}_{\mathrm{MAX}}$ and a minimum value of $\mathrm{L}_{\mathrm{MIN}}$ (normally near zero). Converting the $\mathrm{Q}_{\mathrm{cal}}$ values in the L1T product involves a simple linear rescaling according to:

$L_{\lambda}=\left(\frac{\operatorname{LMAX}_{\lambda}-\operatorname{LMIN}_{\lambda}}{Q_{\text {calmax }}-Q_{\text {calmin }}}\right)\left(Q_{\text {cal }}-Q_{\text {calmin }}\right)+\operatorname{LMIN}_{\lambda}$

where $Q_{\text {calmax }}$ and $Q_{\text {calmin }}$ are 255 and 1, respectively, and $\operatorname{LMAX}_{\lambda}$ and $\mathrm{LMIN}_{\lambda}$ are part of the metadata that is included in the L1T product.

\subsection{Limitations of calibration and uncertainties}

Several of the papers cited previously (Helder et al., 2008, Helder et al., in press-a, in press-b, in press-c) form an extended calibration record for the Landsat series of sensors. Each of these papers gives the uncertainties for the cross-calibration of particular sensor pairs. However, no overall calibration uncertainty for the entire set of Landsat sensors has been presented. If the uncertainties for each sensor pair are considered to be uncorrelated with one another, then the total absolute uncertainty can be calculated through properly summing the individual components orthogonally. Table 11 presents the results of these calculations; values

Table 9

Calibration gain model coefficients for Landsat-5 TM.

\begin{tabular}{lllc}
\hline \multirow{4}{*}{ Band } & \multicolumn{2}{l}{ Model parameters } \\
\cline { 2 - 4 } & $\alpha_{0}$ & $\alpha_{1}$ & $\alpha_{2}$ \\
\hline 1 & 0.2901 & 0.1399 & 1.209 \\
2 & 0.1246 & 0.1045 & 0.63 \\
3 & 0.0839 & 0.2386 & 0.903 \\
4 & 0 & 0 & 1.082 \\
5 & 0 & 0 & 7.944 \\
7 & 0 & 0 & 14.52 \\
\hline
\end{tabular}

Table 10

Gains for Landsat-7 ETM + (DN/(W/m $\left.\left.\mathrm{m}^{2} \mathrm{sr} \mu \mathrm{m}\right)\right)$.

\begin{tabular}{llllllll}
\hline & Band 1 & Band 2 & Band 3 & Band 4 & Band 5 & Band 7 & Band 8 \\
\hline High gain & 1.225 & 1.191 & 1.538 & 1.496 & 7.589 & 21.80 & 1.483 \\
Low gain & 0.8163 & 0.7938 & 1.0245 & 0.9969 & 5.059 & 14.532 & 0.9885 \\
\hline
\end{tabular}


Table 11

Landsat sensor absolute radiometric calibration uncertainties (\%).

\begin{tabular}{|c|c|c|c|c|c|c|c|c|}
\hline & Landsat-7 ETM + & Landsat-5 TM & Landsat-4 TM & Landsat-5 MSS & Landsat-4 MSS & Landsat-3 MSS & Landsat-2 MSS & Landsat-1 MSS \\
\hline Band 1 & 5 & 7 & 9 & 8 & 9 & 9 & 10 & 11 \\
\hline Band 2 & 5 & 7 & 9 & 8 & 9 & 9 & 10 & 11 \\
\hline Band 3 & 5 & 7 & 9 & 9 & 10 & 10 & 11 & 12 \\
\hline Band 4 & 5 & 7 & 9 & 14 & 18 & 18 & 22 & 25 \\
\hline Band 5 & 5 & 7 & 9 & & & & & \\
\hline Band 7 & 5 & 7 & 9 & & & & & \\
\hline Band 8 & 5 & & & & & & & \\
\hline
\end{tabular}

have been rounded to integers, with no real loss of precision, for ease in observing trends. Here it is assumed that the uncertainties for the TM/ $\mathrm{ETM}+$ series of instruments are $5 \%$ for each instrument and each band. The uncertainty for the Landsat-5 TM to MSS calibration process is assumed to be similar to the MSS to MSS calibration process. Finally, for the MSS series, the uncertainties are propagated from sensor to sensor back to Landsat-1 MSS. Pertinent observations from Table 11 indicate that all TM sensors exhibit progressively degraded calibration back to Landsat- $4 \mathrm{TM}$, which is within $9 \%$ absolute. Surprisingly, the MSS series of sensors is also within 10\% absolute radiometric accuracy in all but band 4 . Unfortunately, band 4 is very broad spectrally and includes large atmospheric absorption features. Thus, the uncertainty for this band in the MSS series grows much more rapidly to the point where the absolute uncertainty for Landsat-1 MSS band 4 approaches $25 \%$. Landsat data users need to be aware of these limitations, especially for multitemporal studies.

\section{Summary}

Landsat sensors have recorded the Earth's changes from 1972 through 2011 and provide the longest remote sensing history of our planet available. Until recently, these sensors were not consistently calibrated and the ability to perform extended studies of the earth was limited. Fortunately, recent work has placed all Landsat radiometers (MSS, $\mathrm{TM}$, and ETM +) onto a consistent radiometric scale, and radiometric uncertainties have been quantified. Coefficients for these radiometric gain models were presented. Better yet, these calibration updates have been instituted at the USGS EROS archive and all data currently being distributed contain the most accurate radiometric calibration available. Users of Landsat data now have an unparalleled opportunity to study the history of Earth's land surfaces over the past 40 years.

In December 2012 the Landsat Data Continuity Mission (LDCM), to be called Landsat-8 on completion of commissioning, will be launched. A new generation of pushbroom sensors will be used on LDCM. The design of the sensors, calibration systems, and pre- and post- launch calibration plans have been heavily influenced on the radiometric calibration experiences with earlier Landsat and other sensors. Key aspects retained from the current Landsat systems are: multiple on-board calibration systems, transfer radiometers validating the pre-launch calibration in collaboration with NIST, vicarious measurements, a staffed image assessment system, regular PICS acquisitions and publicly available algorithm descriptions for the data processing. Updated aspects include: radiance, voltage and current monitors on the lamp-based on-board calibration system, three on-board lamps that can be used at different frequencies, dual diffusers made of improved materials (space grade Spectralon ${ }^{\mathrm{TM}}$ ) with greater attention to contamination control, more rigorous pre-launch characterization and calibration including bringing the sun through a heliostat to the solar diffuser and monthly lunar imaging for calibration monitoring.

\section{Acknowledgments}

Calibration of the Landsat instrument series has involved several teams of investigators over the past two decades in order to arrive at the point where these instruments can be used extensively in multi-temporal studies of the Earth's surface. The authors would especially like to thank the Land cover Project Science Office at NASA Goddard Space Flight Center, USGS EROS, university teams at South Dakota State University and the University of Arizona as well as numerous individuals. At the risk of omitting key individuals, the following have made major contributions to this effort:

Darrel Williams, NASA Landsat Project Scientist, 1992-2010; Kristi Kline, USGS Landsat Program Manager, 2005-present, (the free data lady); Jack Kaye, Associate Director Earth Sciences Division, NASA Headquarters; Garik Gutman, Land Cover and Land Use Change Program Manager, NASA Headquarters; James Irons, NASA Landsat Deputy Project Scientist, 1992-2008; John Barker NASA Landsat Associate Project Scientist 1992-2008; Julia Barsi, and Ed Kaita, calibration analysts at NASA's GSFC; Ron Hayes, Image Assessment System Lead, Esad Micijevic, Ron Morfitt, calibration scientists and Gyanesh Chander, all at USGS EROS; Jim Dewald, Dave Aaron, Larry Leigh, and Dave Aaron and many bright students all at SDSU; Phil Teillet, formerly CCRS, for kick starting this effort while on sabbatical at GSFC and Kurt Thome, field calibration Guru, at University of Arizona.

\section{References}

Barker, J. L., Abrams, R. B., Ball, D. L., \& Leung, K. C. (1985). Radiometric calibration and processing procedure for reflective bands on Landsat-4 protoflight Thematic Mapper. Landsat-4 Science Characterization Early Results, NASA CP-2355, II (pp. 47-86).

Butler, J. J., Brown, S. W., Saunders, R. D., Johnson, B. C., Biggar, S. F., Zalewski, E. F., Markham, B. L., Gracey, P. N., Young, J. B., \& Barnes, R. A. (2003). Radiometric measurement comparison on the integrating sphere source used to calibrate the Moderate Resolution Imaging Spectroradiometer (MODIS) and the Landsat 7 Enhanced Thematic Mapper Plus $(\mathrm{ETM}+)$. Journal of Research of the National Institute of Standards and Technology, 108 (3), 199-228.

Chander, G., Xiong, X., Choi, T., \& Angal, A. (2010). Monitoring on-orbit calibration stability of the Terra MODIS and Landsat $7 \mathrm{ETM}+$ sensors using pseudo-invariant test sites. Remote Sensing of Environment, 114, 925-939.

Cosnefroy, H., Leroy, M., \& Briottet, X. (1996). Selection and characterization of Saharan and Arabian desert sites for the calibration of optical satellite sensors. Remote Sensing of Environment, 58, 101-114.

de Vries, C., Danaher, T., Denham, R., Scarth, P., Phinn, S., \& Miller, E. H. (2007). An operational radiometric calibration procedure for the Landsat sensors based on pseudo-invariant target sites. Remote Sensing of Environment, 7(3), 414-429.

Engel, J. L., \& Weinstein, O. (1983). Thematic Mapper-An overview. IEEE Transactions on Geoscience and Remote Sensing, GE-21, 258-265.

Helder, D. (1993). MSS radiometric calibration handbook. USGS EROS final report.

Helder, D., Malla, R., Weyer, L., Mettler, C., Markham, B., Micijevic, E. Landsat 4 Thematic Mapper Calibration Update. IEEE Transactions on Geoscience and Remote Sensing, (in press a).

Helder, D., Karki, S., Bhatt, R., Micijevic, E., Aaron, D. Consistent radiometric calibration of the Landsat MSS sensors. IEEE Transactions on Geoscience and Remote Sensing (in press b).

Helder, D., Aaron, D., Jasinski B. Landsat MSS absolute radiometric calibration. IEEE Transactions on Geoscience and Remote Sensing (in press c).

Helder, D. L., Markham, B. L., Thome, K. J., Barsi, J. A., Chander, G., \& Malla, R. (2008). Updated radiometric calibration for the Landsat-5 Thematic Mapper reflective bands. IEEE Transactions on Geoscience and Remote Sensing, 46(10), 3309-3325.

Helder, D. L., \& Micijevic, E. (2004). Landsat-5 Thematic Mapper outgassing effects. IEEE Transactions on Geoscience and Remote Sensing, 42(12), 2717-2729.

Helder, D. L., \& Ruggles, T. A. (2004). Landsat thematic mapper reflective-band radiometric artifacts. IEEE Transactions on Geoscience and Remote Sensing, 42(12), 2704-2716.

Lansing, J. C., \& Cline, R. W. (1975). The four- and five-band multispectral scanner system for ERTS. Optical Engineering, 14(4), 312-322. 
Malla, R., \& Helder, D. (2008). Radiometric calibration of reflective bands of Landsat 4 Thematic Mapper using pseudo-invariant site technique. Boston: IGARSS 2008.

Markham, B. L., Schafer, J. S., Wood, F. M., Dabney, P. W., \& Barker, J. L. (1998). Monitoring large-aperture spherical integrating sources with a portable radiometer during satellite instrument calibration. Metrologia, 35(4), 643-648.

Markham, B. L., \& Barker, J. L. (1986). Landsat MSS and TM post-calibration dynamic ranges, exoatmospheric reflectances and at-satellite temperatures. EOSAT Tech Notes (pp. 3-8)

Markham, B. L., \& Barker, J. L. (1987). Radiometric properties of U.S. processed Landsat MSS data. Remote Sensing of Environment, 22, 39-71.

Markham, B. L., Boncyk, W. C., Helder, D. L., \& Barker, J. L. (1997). Landsat-7 enhanced Thematic Mapper Plus radiometric calibration. Canadian Journal of Remote Sensing 23(4), 318-332.

Markham, B.L., Haque, M.D.O., Barsi, J.A., Helder, D., Thome, K., Czapala-Myers, J. (2012-this issue) Landsat-7 ETM+: 12 years on-orbit reflective-band radiometric performance. IEEE Transactions on Geoscience and Remote Sensing.

Markham, B. L., Thome, K. J., Barsi, J. A., Kaita, E., Helder, D. L., Barker, J. L., \& Scaramuzza, P. L. (2004). Landsat-7 ETM + on-orbit reflective-band radiometric stability an absolute calibration. IEEE Transactions on Geoscience and Remote Sensing, 42(12), 2810-2820.
Mettler, C., \& Helder, D. (2005). Cross-calibration of the Landsat-4 and Landsat-5 Thematic Mappers. Proc. SPIE, 5882, (07), September 2005.

Metzler, M., \& Malila, W. (1985). Characterization and comparison of Landsat-4 and Landsat-5 Thematic Mapper Data. Photogrammetric Engineering and Remote Sensing, $51,1315-1330$.

NASA (2011). The Landsat Program [www page]. URL http://landsat.gsfc.nasa.gov/.

Schott, J.R., Hook, S.J., Barsi, J.A., Markham, B.L., Miller, J., Padula, F. P., \& Raqueno, N.G. (2012-this issue) Landsat infrared calibration - the entire TM and ETM + archive. Remote Sensing of Enviroment.

Teillet, P. M., Barker, J. L., Markham, B. L., Irish, R. R., Fedosejevs, G., \& Storey, J. C. (2001). Radiometric cross-calibration of the Landsat-7 ETM + and Landsat-5 TM sensors based on tandem data sets. Remote Sensing of Environment, 78, 39-54.

Teillet, P. M., Helder, D. L., Ruggles, T. A., Landry, R., Ahern, F. J., Higgs, N. J., Barsi, J., Chander, G., Markham, B. L., Barker, J. L., Thome, K. J., Schott, J. R., \& Palluconi, F. D. (2004). A definitive calibration record for the Landsat-5 Thematic Mapper anchored to the Landsat-7 radiometric scale. Canadian Journal of Remote Sensing, 30 (4), 631-643. 